\title{
O frisson da bailarina: o funcionamento semântico- enunciativo do nome baderna
}

\author{
The frisson of the dancer: the semantic and enunciative operation of the name \\ baderna
}

\author{
Taisir Mahmudo Karim ${ }^{1}$ \\ Universidade do Estado de Mato Grosso \\ Lucas Alvares ${ }^{2}$ \\ Universidade do Estado de Mato Grosso \\ Albano Dalla Pria ${ }^{3}$ \\ Universidade do Estado de Mato Grosso
}

\begin{abstract}
- RESUMO: os sentidos de uma palavra se dão no e pelo acontecimento de enunciação pelo qual uma palavra, um termo, uma expressão funciona nomeando algo, uma pessoa ou simplesmente se articulando por modos específicos em um texto. Nosso objetivo aqui, é o de observar o funcionamento semântico/enunciativo da palavra/termo baderna que passa a funcionar no léxico que compõe a língua portuguesa do Brasil a partir de um dado momento da história, constituindo um significado que desloca o termo do lugar de um nome próprio de pessoa para a nomeação de um comportamento negativo em certos momentos. Para tanto, valer-nos-emos da teoria da semântica do acontecimento de Guimarães (2002) como norte teórico e metodológico para nossas análises da palavra/termo baderna nos textos selecionados para este trabalho.
\end{abstract}

- PALAVRAS-CHAVE: Semântica; Acontecimento; Baderna.

- ABSTRACT: The meanings of a word happen in and through the enunciation event whereby a word, a term, an expression works by naming something, a person, or simply articulating itself in specific ways in a text. Our objective here is to observe the semantic / enunciative functioning of the word / term baderna that starts to function in the lexicon that composes the Portuguese language of Brazil from a certain moment in history, constituting a meaning that moves the term from the place of a proper personal name for naming negative behavior at certain times. To this end, we will use the theory of semantics of event of Guimarães (2002) as the theoretical and methodological direction for our analyzes of the word / term baderna in the texts selected for this work.

- KEYWORDS: Semantics; Event; Baderna.

\section{Uma primeira localização}

\footnotetext{
${ }^{1}$ Doutor em Linguística pela UNICAMP. Professor do PPGL/DL UNEMAT/Cáceres, coordenador do projeto de pesquisa Significar Mato Grosso.

${ }^{2}$ Doutorando em Linguística/PPGL/Unemat, membro do projeto de pesquisa Significar Mato Grosso.

${ }^{3}$ Doutor em Linguística e Língua Portuguesa pela UNESP/FCL/Araraquara. Professor do PPGL/UNEMAT.
} 
Em algum momento de nossa vida já ouvimos, lemos ou dissemos o nome baderna. Sua significação, considerando seu funcionamento no espaço de enunciação 4 do português brasileiro, atualmente nos leva a sentidos correlatos ao de confusão, desordem, bagunça, caos, algazarra, anarquia, diríamos, para uma direção argumentativa construída por uma rede semântica ${ }^{5}$ de negatividade (no sentido mesmo raso de algo ruim). No entanto, como é sabido, os sentidos de um nome não são unívocos e muito menos uno direcional(sinonímicos),ou seja, eles não podem se resumir na relação dicionarizada, sentidos já pré estabelecidos, eles são múltiplos (polissêmicos), contraditórios muitas vezes.Isso se deve ao fato de os sentidos serem construídos no acontecimento do dizer, ou melhor, são constitutivos do acontecimento enunciativo, e é por esse movimento semântico que a língua se propõe sempre instável, opaca, não transparente.Neste artigo, interessa esse lugar de observação, o lugar que nos mostra esse movimento semântico, um estudo da significação de nomes. Tomamos, aqui como objeto de análise, a palavra/nome baderna.Nosso corpus se constitui de três recortes: o primeiro retirado do site terra ${ }^{6}$; o segundo, uma capa de revista, retirado da ISTOÉ de junho de 2018, com a manchete "Sob o signo do caos", o terceiro recorte retiramos da capa da revista Veja de 03 de abril de 2019, intitulado "A incrível baderna na educação".

Apresentaremos,inicialmente, nossa posição enquanto linguistas e assim, o direcionamento teórico-metodológico que tomaremos para as análises dos recortes. A posição assumida por nós é a do semanticista, aquele que trata dos estudos da significação da/na linguagem; nossa posição teórica toma os estudos enunciativos tal quais estão sustentados em semânticas que consideram que os sentidos se constituem na enunciação(GUIMARÃES, 2002, 2011, 2018 e DIAS, 2013, 2018).Essa posição tomo os estudos da significação no acontecimento do dizer, na relação entre língua, história e falante, este constituído enquanto sujeito ao ser tomado pela língua no seu funcionamento.

Para nós, observar o acontecimento do dizer é observar a historicidade constitutiva da linguagem "[...] enquanto diferença em sua própria ordem" (GUIMARÃES, 2002), ou seja, é considerar o acontecimento como algo que instala uma temporalidade própria e específica. Ao instalar sua temporalidade, o acontecimento enunciativo recorta enunciados outros enquanto memorável ${ }^{7}$. São enunciados já ditos constitutivos do presente do acontecimento.

Como dissemos acima, neste estudo, nossas análises levam em consideração o movimento semântico do nome baderna, movimento esse construído a partir de sua história de enunciação.Para tanto, devemos, primeiro, considerar a trama sócio-histórico enunciativa da palavra/nome que se articula de forma transversal ${ }^{8}$ em acontecimentos diversos. Essas são condições que se apresentam enquanto traços de linguagem, que, em funcionamento, instala uma temporalidade própria do acontecimento $\mathrm{e}$ forja,assim,sentidos constitutivos de sua própria história de enunciação a partir das redes enunciativas ${ }^{9}$ do dizer.Vale lembrarmos aqui, que os sentidos do presente do

\footnotetext{
${ }^{4}$ Conforme conceitua Guimarães em Semântica do Acontecimento (2002).

${ }^{5}$ Nos termos que damos enquanto palavras que se apresentam na relação sinonímica e que sustentam um argumento $\mathrm{x}$ em detrimento ao $\mathrm{y}$.

${ }^{6}$ https://www.terra.com.br/noticias/educacao/voce-sabia/qual-a-origem-da-palavrabaderna,b3e033f966dcf310VgnVCM20000099cceb0aRCRD.html.

${ }^{7}$ Que não se constitui no dizer como lembrança pessoal de fatos ocorridos na história.

${ }^{8}$ Conforme Guimarães (2011).

${ }^{9}$ Conforme definição em Dias (2018).
} 
acontecimento, abre em si condições de uma futuridade enunciativa (enunciados futuros), sempre recortado por um memorável.

Para que possamos considerar os sentidos do nome/palavra baderna em enunciados que constituem os recortes que compõem o corpus desta análise, vamos mobilizar alguns dos dispositivos analíticos dos construtos teóricos da Semântica do Acontecimento/Enunciação.

Dentre os dispositivos teórico-metodológicos disponíveis trazemos o processo de articulação e reescrituração ${ }^{10}$,a caracterização e constituição do espaço de enunciação $^{11}$ e a configuração da cena enunciativa.Esses suportes analíticos nos permitirão uma observação capaz de apresentar a descrição dos lugares sociais de dizer tomados pelos sujeitos falantes, ou seja, a configuração que se apresenta no momento mesmo do acontecimento pelo agenciamento enunciativo das figuras enunciativas.

Compreender o funcionamento de linguagem da posição de uma semântica enunciativa e histórica coloca-nos a considerar o acontecimento de modo diferente daqueles que o tomam por uma posição pragmática ou funcionalista, muito menos daqueles que o tomam pelo referencialismo. Nesse sentido, nossas análises se darão considerando-se o acontecimento do dizer na sua relação sócio-histórica. Assim, para nós, a relação designativa do nome/palavra baderna se apresenta construída no acontecimento do dizer. A observação do funcionamento da língua, nesse sentido, tem de consideraro enredo histórico enunciativo do nome em análise.

\section{De lá pra cá: a entrada do termo no léxico do Português do Brasil - uma relação ítalo/brasileira}

O nome baderna não tem origem na língua portuguesa do Brasil. Ele entra no espaço de enunciação do português do Brasil através da língua italiana. Esse registro se dá durante o século XIX. O nome é enunciado pela primeira vez no Brasil como sobrenome de uma dançarina italiana, "Marietta Baderna". A dançarina chega ao Brasil como integrante de uma companhia de dança italiana. Conta-se que "Marietta Maria Baderna" era uma jovem encantadora e que, em suas apresentações, causava um enorme frisson, furor nos fãs que a assistiam. Esses fãs foram nomeados pela expressão "os badernas", a expressão, uma junção de fãs (os) mais Baderna, é assim uma formação nominal ${ }^{12}$ construída metonimicamente a partir da relação entre o nome da dançarina, sua performance e os fãs.O nome Baderna, por um processo de repetição,renomeia, nesse caso, os fãs de "Marietta Maria Baderna","os badernas" (fãs de Baderna).A seguir vamos observar o funcionamento desse processo no recorte (R1) abaixo, retirado da história da palavra, contada pelo site Terra:

R1

\footnotetext{
${ }^{10}$ Este é um procedimento teórico de retomada de um texto, uma expressão ou uma palavra que pode se dar por diferentes formas como por substituição, repetição, anáfora, expansão etc.

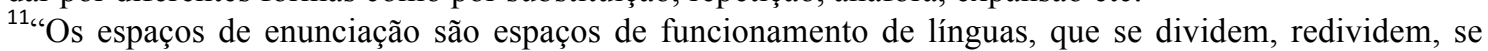
misturam, desfazem, transformam por uma disputa incessante. São espaços 'habitados' por falantes, ou seja, por sujeitos divididos por seus direitos ao dizer e aos modos de dizer” (GUIMARÃES, 2002, p. 18).

${ }^{12}$ Nos termos de Dias (2018).
} 


\section{Qual a origem da palavra "baderna"? \\ Termo servia para caracterizar fãs barulhentos da dançarina Maria Baderna}

Baderna é uma palavra exclusiva do português brasileiro que significa confusão, desordem, bagunça. Mas sua origem é bem peculiar: servia para classificar, de maneira pejorativa, os seguidores barulhentos de uma dançarina italiana que causou furor no País. Seu nome? Maria Baderna.

A palavra que hoje define a ausência de regras surgiu no final do século 19, quando uma companhia de dança italiana veio à então capital do Império do Brasil, o Rio de Janeiro. A viagem era uma forma de manifestação contra a perseguição politica: ocupada pela Áustria, a Itália mantinha como forma de protesto entre os revolucionários a decisão de não promover a vida artística enquanto a ocupação durasse.

Parte dessa companhia, a bailarina Marietta Maria Baderna, filha do médico e músico Antônio Baderna, teria buscado o Brasil como exílio em 1849. Talentosa, logo conquistou uma legião de fãs, admiradores tanto de seus passos de dança quanto de seu espírito rebelde e contestador. Inovadora, ela foi alvo de críticas ao introduzir elementos do lundum (dança afrobrasileira praticada por escravos) entre os passos da dança clássica - em meio a uma sociedade conservadora e escravista.

Maria Baderna esteve no Rio de Janeiro em 1851, provocando "um certo frisson", de acordo com o dicionário Houaiss. O termo "baderna" está associado aos seus admiradores, chamados de "os badernas", que entoavam o nome da musa ao final de suas apresentações. O coro era mal visto pela sociedade da época, que associou o barulho e a paixão incontida dos fãs a algo ruim.

Fonte:https://www.terra.com.br/noticias/educacao/voce-sabia/qual-a-origem-dapalavra-baderna,b3e033f966dcf310VgnVCM20000099cceb0aRCRD.html. Acessado em 11 de abril de 2019.

É nesta direção que nos interessa observar o funcionamento enunciativo do nome/palavra, um funcionamento semântico plural: por um lado temos o nome Baderna determinando parte constitutiva da identidade da dançarina italiana "Marietta Maria Baderna"; por outro, o deslocamento semântico, "os badernas",que reescreve por condensação "seguidores barulhentos", "admiradores" e "fãs"13. Nesse sentido, a formação nominal, "os badernas" ao ser enunciada como nome que reescreve "seguidores barulhentos", "admiradores" e "fãs", esse movimento, acaba por construir sentidos que, apresentam relações opositivas entre "Baderna/os badernas". Assim, temos Baderna, de um lado, para"Marietta Maria Baderna",isto é, o nome constitui a identidade da dançarina italiana que causa.Temos então,no recorteR1; "dançarina italiana" determinando "Maria Baderna", aquela que causa furor, frisson. De outro, a formação nominal, "os badernas",é determinada por "seguidores barulhentos", "admiradores" e "fãs". Neste funcionamento, os sentidos para "os baderna" são construídos pelo processo de reescrituração por substituição,"os baderneiros" reescreve" seguidores barulhentos", "admiradores" e "fãs", ou seja, "seguidores barulhentos", "admiradores" e "fãs" determinam "os badernas".Esse deslocamento semântico é construído pela articulação por incidência, pois se pode dizer que "Mas sua origem é bem peculiar:" articula-se (incide) com o que se segue no texto "[...] servia para

\footnotetext{
${ }^{13}$ Estes em uma relação sinonímica.
} 
classificar, de maneira pejorativa, os seguidores barulhentos de uma dançarina italiana que causou furor no País.”. Com efeito, temos uma explicação para esse deslocamento que se constrói pela articulação e reescrituração que recai sobre a formação nominal "os badernas"e, ao mesmo tempo,a retomada do nome "Baderna" trazida pela reescrituração anafórica "sua" nos mostra, em R1, que, em certa medida,"Baderna/dançarina italiana"é determinada pelo "os badernas/seguidores barulhentos-fãs-admiradores, essa determinação argumenta, em certa medida, para a contemplação do feito da dançarina.Ao mesmo tempo, podemos observar, pelo processo de articulação e reescrituração,que "confusão, desordem, bagunça, maneira pejorativa, paixão incontida, barulho, algo ruim",ao articular com "os badernas"("seguidores barulhentos", "admiradores" e "fãs"),acabam por construir uma rede semântica de direção negativa para a formação nominal.

Como visto acima, o funcionamento do nome/palavra "baderna"apresenta relações designativas constitutivas de sua história de enunciação, no espaço de enunciação do português do Brasil.Essa relação designativa constrói sentidos que determinam não só a identidade da bailarina italiana (Marietta Maria Baderna),o funcionamento do nome/palavra "baderna"acrescido do definidor "os" constrói sentidos que são determinados pela reescrituração de "seguidores barulhentos", "admiradores" e "fãs", estes articulados com os termos "confusão", "desordem", "bagunça", "maneira pejorativa","mal visto", "algo ruim".Temos, então, que o termo "baderna", ao funcionar enunciativamente, nesse acontecimento,apresenta sua pluralidade semântica.Ou seja, nesse percurso de enunciação, o nome/palavra "baderna" aponta para duas redes semânticas com direções argumentativas distintas: uma que constrói sentidos para relações designativas como "causar furor, provocar frisson, admiração, paixão incontida", uma sustentação de argumentação positiva (alegria, felicidade);e outra, para sentidos como "confusão", "desordem", "maneira pejorativa", "bagunça", "mal visto", "algo ruim", que sustenta uma argumentação para o nome negativamente (caos, anarquia). No caso específico desse R1, estes sentidos, recaem apenas sobre "baderna" acrescido do definidor "os", definidor que reescreve anaforicamente,seguidores barulhentos, admiradores e fãs.

Passemos, agora, aos recortes retirados de duas revistas de grande circulação nacional: a ISTOÉ, edição 2528, de maio de 2018, e a Veja, de 03 de abril, de 2019. A primeira apresenta, na capa, a situação da "greve dos caminhoneiros" ocorrida naquele mesmo ano, enquanto a segunda trás como chamada de capa a "crise no MEC".

\section{Dois recortes: consideraçõesque semantiza o nomebaderna}

Partiremos, agora,da consideração,de que o nome/palavra "baderna"assume, no seu funcionamento, função tanto de determinação quanto predicativa.Essas funções constroem a relação designativa que significa o movimento polissêmico do próprio nome,no acontecimento do dizer.Esse movimento marca a flutuação semântica construída no e pelo percurso histórico constitutivo do nome.

Como já observado na seção anterior, o nome/palavra "baderna", em um primeiro caso, determina a identidade da bailarina italiana "Marietta Maria Baderna", na relação com "causar furor", "provocar frisson", "admiração", "paixão incontida", termos que permite construir uma rede semântica positiva. Num segundo, o termo acrescido do definidor "os"é determinado por "seguidores barulhentos", "admiradores", "fãs". Estes na relação de articulação com "confusão", "desordem", "maneira pejorativa", "bagunça", "mal visto", "algo ruim", acaba por construir uma rede semântica negativa. 
Esses movimentos enunciativos apresentam as relações designativas que deslocam sentidos do nome/palavra "baderna".Como vimos, esses movimentos deslocam sentidos, acabam por construir sentidos que sustentam direções argumentativas distintas,ou seja, essas são relações designativas que constroem sentidos na sua relação com o real da língua, o que permite uma observação plural constitutiva da história de enunciação no nome.

A seguir, vamos observar os outros dois recortes.

\subsection{R2 - Entre o caos e a baderna uma possível relação sinonímica}

O R2, traz um enunciado que fora retirado da capa da revista ISTOÉ, coma seguinte Manchete: "SOB O SIGNO DO CAOS".Logo abaixo da chamada segue-se um pequeno texto,no qual o nome baderna é enunciado, conforme podemos verificar a seguir:

(R2)

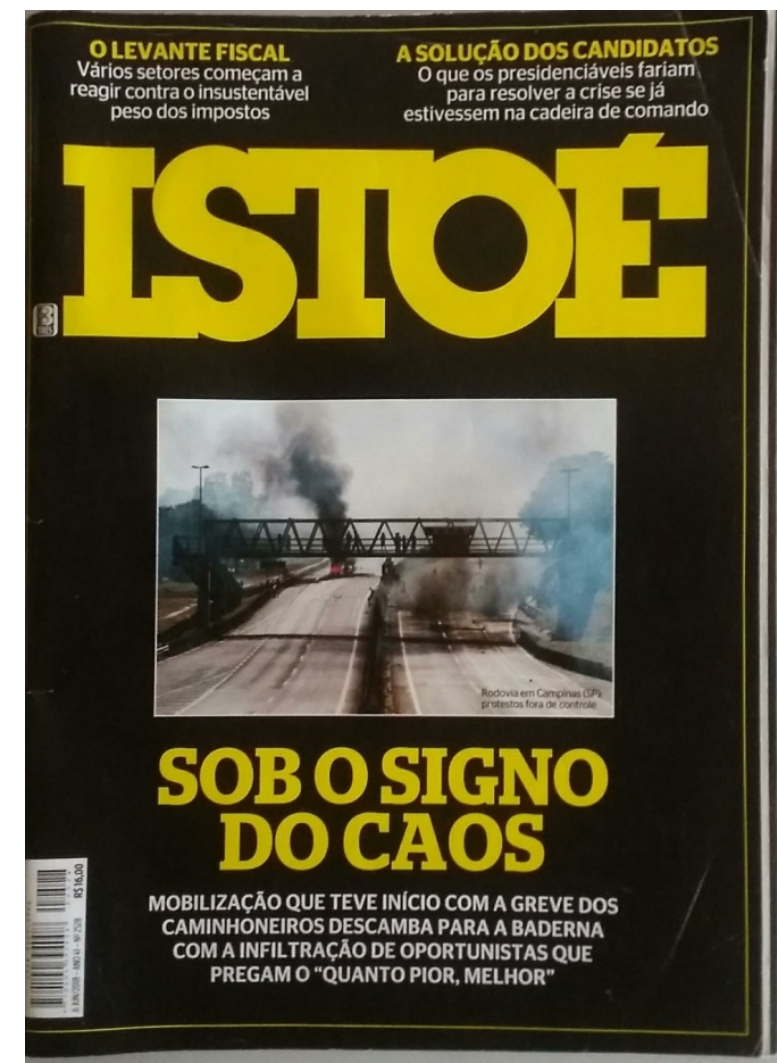

\section{SOB O SIGNO DO CAOS}

Mobilização que teve início com a greve dos caminhoneiros descamba para a baderna com a infiltração de oportunistas que pregam o 'quanto pior, melhor' 
Observamos em R2, de entrada, o procedimento de reescrituração do nome. Esse procedimento se dá de dois modos distintos: no primeiro, o enunciado "Mobilização que teve início com a greve dos caminhoneiros descamba para a baderna com a infiltração de oportunistas que pregam o "quanto pior, melhor" reescritura por expansão a formação nominal título da chamada "Sob o signo do caos".O enunciado, diz o que é "Sob o signo do caos".Ao fazê-lo,constrói aquilo que significa "baderna",nesse acontecimento; no segundo, tem-se a reescrituração do termo "caos", este é reescriturado por substituição por "baderna".Esse procedimento coloca "baderna" determinando "caos" ambos em relação sinonímica.Assim, parece nos razoável a paráfrase (") "SOB O SIGNO DA BADERNA". Outra paráfrase que nos parece razoável (")"Mobilização que teve início com a greve dos caminhoneiros descamba para o caos com a infiltração de oportunistas que pregam o "quanto pior, melhor"". Considerando essas paráfrases é possível sustentar o funcionamento sinonímico entre baderna/caos. Podemos ainda dizer que baderna/caos se articulam com "quanto pior, melhor", sem que,com isso,aja prejuízo semântico com a inversão dos termos.Dessa forma baderna/caos têm seus sentidos construídos e sustentados pela articulação que incide sobre "quanto pior, melhor".

No primeiro caso, os sentidos construídos movem-se numa direção pela qual o título "SOB O SIGNO DO CAOS" é significado por tudo aquilo que é dito abaixo. Já, no segundo,"baderna", ao reescrever por substituição o termo "caos",esse procedimento,constrói sentidos que sustentam o lugar da desordem. O enunciado "Mobilização que teve início com a greve dos caminhoneiros descamba para a baderna [...]" pode ser parafraseado por: (") "mobilização que teve início com a greve dos caminhoneiros descamba para a desordem [...]". Observa-se que a paráfrase pode substituir o enunciado que integra o texto "original".Valendo-nos desse procedimento de paráfrase, podemos observar que o nome/palavra "baderna", funciona no acontecimento de enunciação, constituindo sentidos de algo nocivo à mobilização dos caminhoneiros. Nesta direção, descambar para a "baderna"é o mesmo que descambar para o caos, considerando os sentidos construídos pela articulação que incide sobre" quanto pior, melhor".

No caso do enunciado "Mobilização que teve início com a greve dos caminhoneiros descamba para a baderna com a infiltração de oportunistas que pregam o 'quanto pior, melhor'", há uma articulação tal que o sentido de "baderna" é determinado, de um lado, por "caos", que aparece no título do texto, e por outro, "baderna" está articulada por coordenação argumentativa em "[...] com a infiltração de oportunistas que pregam o 'quanto pior, melhor"'.Ainda, ao observarmos a segunda parte do enunciado verifica-se uma relação de articulação entre "oportunistas" com "quanto pior, melhor". Nesse sentido, "a mobilização descamba para a baderna" se articula com "quanto pior, melhor", ou seja, a expressão "Quanto pior, melhor" acaba por determinar o termo "baderna" no enunciado.Nesse caso, "baderna"está para "quanto pior, melhor".

O enunciado "Mobilização que teve início com a greve dos caminhoneiros descamba para a baderna [...]", apresenta por si só consistência interna e independência relativa. Porém, aquilo que predica o primeiro enunciado acaba por determinar o sentido do todo, incluindo-se o sentido para "baderna"que é sustentado por "quanto pior, melhor".

Na relação de articulação por contiguidade do texto, os sentidos são constituídos numa relação entre o determinante e o determinado na qual o enunciado "quanto pior, melhor" determina o nome/palavra "baderna". Por outro lado, considerando-se a relação de articulação e o procedimento de reescrituração, o termo "caos", que funciona no 
título do texto, é retomado por "baderna" determinando, assim, o sentido do nome/palavra "baderna".

\subsection{R3 -Sentidos anárquicos}

(R3)

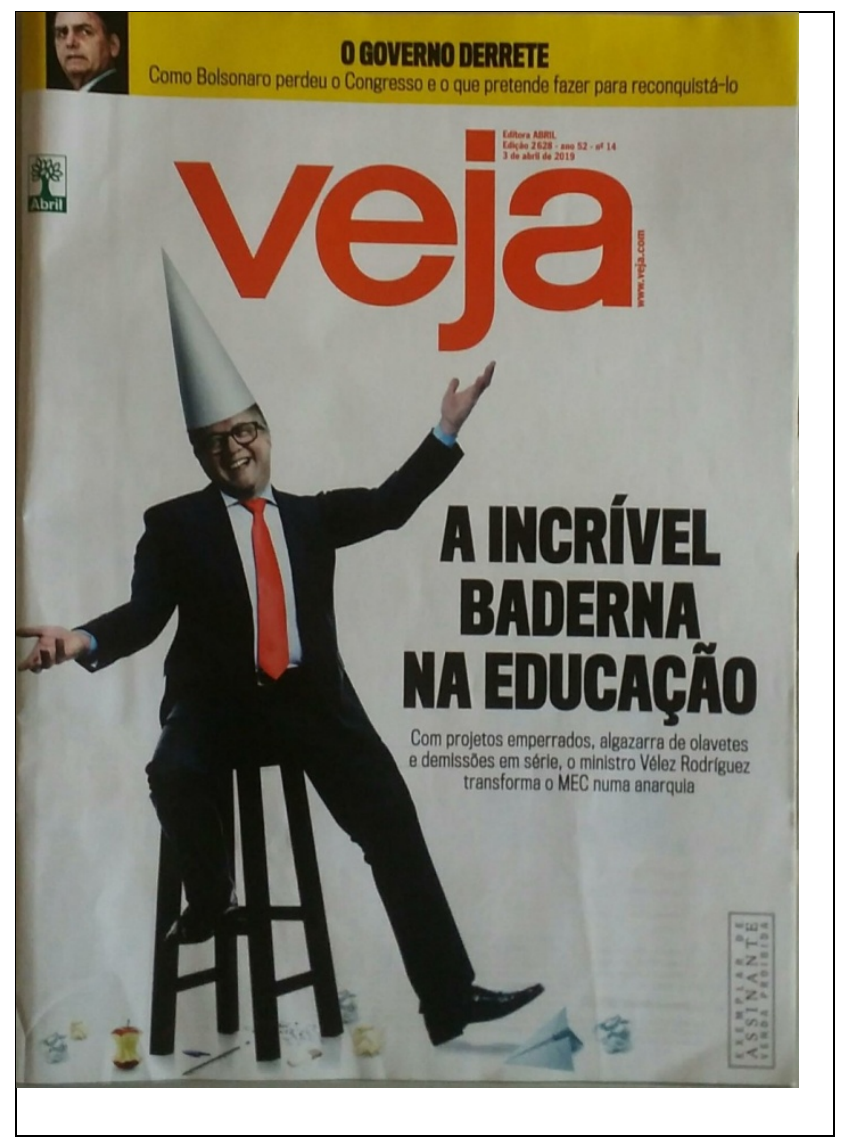

Passaremos agora às considerações do recorte $(\mathbf{R 3})$ retirado da revista Veja. Vejamos o enunciado do recorte:

(R3)

\section{A INCRIVEL BADERNA NA EDUACAÇÃO}

Com projetos emperrados, algazarra de olavetes e demissões em série, o ministro Vélez Rodríguez transforma o MEC numa anarquia.

Em R3, no título da chamada "A INCRÍVEL BADERNA NA EDUCAÇÃO”, o nome/palavra "baderna" aparece articulado com o elemento qualificador "incrível".Essa relação constrói sentidos para "baderna" na direção de "espanto/exagero", ou seja, uma "baderna"maiúscula.Nesse caso, em particular, o termo funciona predicando Educação no Brasil. Esse funcionamento de articulação e predicação permite-nos formular a seguinte paráfrase: (",') "A educação brasileira está um verdadeiro caos".Assim, o título funciona, na relação que coloca em questão o determinante, ("a incrível baderna"), e o determinado, ("na educação"). 
Podemos parafrasear o título por:(',,') "A espantosa baderna na educação". Os sentidos construídos nesse funcionamento enunciativo argumentam na direção de uma certa descrença com a política educacional no país.Com efeito, o elemento qualificador "incrível", que determina "baderna"no enunciado, não constitui, semanticamente, sentidos que direcionam para algo bom, mas, ao contrário, para algo negativo.

Observa-se ainda que há uma relação no texto que funciona pelo procedimento de reescrituração. O título como um todo é reescriturado pelo enunciado que compõe o texto da chamada de capa da revista. Ou seja, o título é retomado e significado por todo o enunciado que vem depois dele. Esse procedimento de reescrituração por expansão especifica o que significa a "incrível baderna" trazida pelo título do texto.

O nome/palavra "baderna" é também reescriturado por substituição, constituindo uma relação sinonímica, esse modo de reescrituração aparece duas vezes no curso do texto, primeiro,"baderna"é reescriturada por "algazarra" e depois por "anarquia", isso pode ser descrito ao tomarmos as reescriturações a partir de processos parafrásticos, assim teríamos (',,,,') "com projetos emperrados, baderna de olavetes (...)", e, (',,,,') "o ministro Vélez Rodríguez transforma o MEC numa baderna". As duas paráfrases se mostram suficientes para que possamos considerar o sentido sinonímico construído no procedimento de reescrituração por substituição. Da mesma forma podemos observar que os termos "algazarra" e "anarquia" são passíveis de substituição no enunciado título. Podemos parafrasear o título por (",,,,,,) "A incrível algazarra na educação", ou (',,,,,,) "A incrível anarquia na educação". Os sentidos construídos a partir destas paráfrases sustentam movimentos que direcionam para uma rede semântica que passa a significar a educação brasileira como algo negativo.

"Baderna" é aqui determinado por "incrível" num sentido muito particular de "espanto". Esse sentido é construído na relação de articulação do nome/palavra com "bagunça" e "desordem". Ao estabelecer uma relação sinonímica com "algazarra" e "anarquia" podemos observar que as paráfrases acima nos mostram como os sentidos se conformam em que o que é "incrível" é a "algazarra" e a "anarquia" que se instala no MEC.

Esses dizeres se apresentam por uma articulação que produz, a argumentação no presente do acontecimento, são sentidos que se sustentam pela divisão política que se instala na temporalidade do dizer. A argumentação funciona, na enunciação, na direção de "projetos emperrados" e "demissões em série" e se articulam a "baderna"por uma relação de coordenação,ou seja, só há "baderna" porque há projetos emperrados e demissões em série no MEC.

As articulações construídas pelo acontecimento enunciativo do título são sustentadas pelas articulações e reescriturações construídas entre o título (chamada) e o texto. Se há uma "incrível baderna na educação" é porque "há projetos emperrados e demissões em série".E, "se há baderna é por que há algazarra e anarquia". "Projetos emperrados" e "demissões em série"articulam de modo coordenado com a formação nominal "a incrível baderna", esse movimento sustenta a direção argumentativa daquilo que se diz em relação ao MEC. De igual modo, as relações de reescrituração de"baderna", "algazarra" e "anarquia" sustentam os sentidos de "baderna"por uma relação de reescrituração sinonímica.

A relação de argumentação constituída no texto segue a direção que constrói sentidos para "baderna" significando lugar de negatividade. "Baderna" nesse caso significa algo "ruim", "nocivo" à educação no/do Brasil. "Com projetos emperrados", "algazarra de olavetes" e "demissões em série" se articulam no texto com a formação nominal "A incrível baderna".Essa articulação coordenativa acaba por determinar os sentidos de "baderna", que predica a educação brasileira. Semelhantemente,o enunciado 
"o ministro Vélez Rodríguez transforma o MEC numa anarquia", funciona numa relação de articulação por coordenação sobre a formação nominal "A incrível baderna" reiterando sentidos de "baderna"nesse acontecimento.

Assim, "Com projetos emperrados", "algazarra de olavetes" e "demissões em série" funcionam como argumentos que sustentam sentidos que passam a significar o MEC uma incrível "baderna".E isso se dá pelas relações de articulação e reescrituração presentes no texto, esses procedimentos constrói a relação sinonímica entre "anarquia" e "baderna".

\section{CONCLUSÃO}

Ressaltem-se as diferenças que se constituem quanto ao funcionamento do nome/palavra "baderna" nos acontecimentos enunciativos que compõem os recortes R1, R2 e R3. Em R1 o nome funciona significando em duas direções: uma marcada pela relação de articulação de dependência, a que determina "Marietta", isto é, Marietta é Baderna, é da família dos Baderna, ou seja, funciona enquanto nome que determina a identidade de uma família em particular; outra, marcada pela constituição da formação nominal que deriva do nome "Baderna", "os badernas".Essa formação nominal reescritura "seguidores barulhentos", "admiradores" e "fãs" da dançarina italiana "MariettaMaria Baderna". Em R2, o nome "baderna"funciona por uma relação de articulação coordenativa argumentativa designando oportunistas que se infiltraram na mobilização dos caminhoneiros para provocar o caos e pregar o "quanto pior, melhor", essa articulação leva em consideração a relação sinonímica entre "baderna/caos".Já, em R3, o nome funciona significando o "estado" da educação brasileira.

$O$ que se pôde observar até aqui sobre os sentidos constitutivos de um nome/palavra é que eles não se constroem apenas nas relações de articulação e reescrituração de um texto. Os sentidos são construídos levando em consideração a temporalidade específica instituída pelo e no acontecimento de dizer, um acontecimento atemporal, que recorta enunciações outras (o memorável), como também abre em si sua latência de futuridade, essa temporalidade é marcada pela conviviabilidade dos tempos no presente do acontecimento. Ou seja, a história de enunciação de uma nome/palavra não se dá por uma relação pré-estabelecida no tempo como numa segmentalidade temporal diacrônica, mas, sim, no funcionamento enunciativo. O nome/palavra, ao funcionar em um acontecimento enunciativo particular, institui uma temporalidade específica e recorta como memoráveis enunciações específicas. A mobilidade do relevo semântico do nome/palavra "baderna" permite afirmar que os sentidos não são estanques, eles são construídos no acontecimento do dizer, são constitutivos da história enunciativa do nome/palavra.

"Baderna" é um nome/palavra exclusivo da Língua Portuguesa enquanto termo que institui relação sinonímica com "confusão", "caos" e "desordem". Sua entrada na língua se dá pela língua italiana, através de um sobrenome que determina alguém como pertencente à família Baderna. Com efeito, relacionando-se os espaços de enunciação da língua italiana e do português é possível estabelecer uma diferença de sentidos pela qual "Baderna"na língua italiana significa um nome que designa a família "Baderna" e no espaço de enunciação do português do Brasil o nome/palavra "baderna" sofre um deslocamento semântico. Como visto nas análises, o termo passa a significar o comportamento social de desordem, caos, anarquia.

A significação de um nome/palavra não se resume aos estudos etimológicos ou de uma lexicografia de significados já estabilizados num dado contexto de enunciação. Os sentidos de um nome/palavra são produzidos no acontecimento de enunciação num 
espaço de enunciação específico considerando seu funcionamento na linguagem. Ou seja, os sentidos são produzidos no presente do acontecimento ao recortar como memorável algo de sua história enunciativa. Abre-se, assim, uma latência de futuridade que se instala como o lugar da interpretação, de novas enunciações. É exatamente por isso que "baderna"não só nomeia alguém pertencente a uma família, mas também designa o comportamento social de pessoas ou de grupos de pessoas no seio do convívio social. As diferenças semânticas se instalam no presente do acontecimento, no funcionamento do nome/palavra em enunciados e não enquanto "produtos" da intenção de quem diz ou do contexto em que se diz. Nos recortes escolhidos como corpus, o deslocamento de sentidos de "baderna", constitutivos da história enunciativa do nome/palavra, constrói argumentos na direção de uma divisão que coloca, de um lado, "alegria", "prazer" e, de outro, "caos", "anarquia". Com efeito, os sentidos produzidos na relação do nome/palavra com a história, são sentidos que, de um lado, comungam de uma rede semântica, de outro, contradizem essa rede, ou seja, constroem outra rede que argumenta em direção contrária. Eles dividem o real da história entre aquilo que se espera e aquilo que não se quer, entre a alegria e a confusão, eis o político de (B)baderna.

\section{REFÊNCIAS}

DIAS, Luiz Francisco. Enunciação e relações linguísticas. Campinas, SP, Ed. Pontes, 2018.

GUIMARÃES, Eduardo. Semântica do Acontecimento. Campinas, SP, Ed. Pontes, 2002 .

2011.

Análise de Texto - Procedimentos, Análises, Ensino . Campinas, SP, Ed. RG,

Semântica Enunciação e Sentido. Campinas, SP, Ed. Pontes, 2018.

KARIM, Taisir Mahmudo. Mato Grosso: histórias de enunciações o percurso do nome de um estado. In: KARIM, Taisir Mahmudo. [et al.] (Org.). Atlas dos nomes que dizem histórias das cidades brasileiras: um estudo semântico-enunciativo do Mato Grosso - (Fase I). Campinas-SP. Pontes, 2016.

Marcas do Dizer: Sentidos do Arraial do Cuyabá. In: Estudos Linguísticos, 45 (1), São Paulo, p. 305-315, 2016.

; ALVARES, L.De incivilizados a descivilizados: um percurso semântico do nome vândalos. In: ORLANDI, Eni. [et al.] (Org.). Linguagem, Instituições e Práticas sociais. Pouso Alegre, MG. Univás. 2018.

; SILVA, G. V. da; MACEDO KARIM, J. O contorno linguístico de uma geografia - mato grosso e seus mapas: a constituição do atlas mato-grossense a partir do acontecimento de nomeação. In: GUIMARÃES, Eduardo [et al.] (Org.). Atlas dos nomes que dizem histórias das cidades brasileiras: um estudo semântico-enunciativo do Mato Grosso - (Fase II). Campinas-SP. Pontes, 2018.

Recebido em: novembro de 2019. Aprovado em: dezembro de 2019.

Como citar este trabalho:

KARIM, T. M.; ALVARES, L. PRIA, A. D. O frisson da bailarina: o funcionamento semântico-enunciativo do nome baderna. Traços de Linguagem. V.3, n.2, p. 16-27, 2019. 
Traços de Linguagem, Cáceres, v. 3, n.2, p. 16-27, 2019. 